\title{
Designing MOOCs to Facilitate Participant Self-Monitoring for Self-Directed Learning
}

\author{
Meina Zhu \\ Wayne State University \\ Curtis J. Bonk \\ Indiana University
}

\begin{abstract}
This study investigated the design and delivery of MOOCs to facilitate student self-monitoring for self-directed learning (SDL) using mixed methods. The data sources of this study included an online survey with 198 complete respondents, semistructured interviews with 22 MOOC instructors, and document analysis of 22 MOOCs. Study results indicated that MOOC instructors considered self-monitoring skills critical for SDL. To foster students' self-monitoring, MOOC instructors reported that they facilitated students' self-monitoring by helping students with internal feedback and providing external feedback. Students' internal feedback included cognitive and metacognitive processes. To facilitate cognitive processes, MOOC instructors provided quizzes, tutorials, learning strategies, learning aids, and progress bars. For metacognition, these instructors provided reflection questions and attempted to create learning communities. In addition, MOOC instructors, teaching assistants, and peers provided external feedback for students' self-monitoring. Across these findings, technology played a central role in supporting students' self-monitoring.

Keywords: massive open online courses (MOOCs), self-monitoring, self-directed learning, instructional design, MOOC instructors

Zhu, M., \& Bonk, C.J. (2019). Designing MOOCs to facilitate participant self-monitoring for self-directed learning. Online Learning, 23(4), 106-134. doi:10.24059/olj.v23i4.2037
\end{abstract}

\section{Designing MOOCs to Facilitate Participant Self-Monitoring for Self-Directed Learning}

Previous studies have argued that self-directed learning (SDL) is critical to adult education (Garrison, 1997; Merriam, 2001). Given that most MOOC learners are adults (Shah, 2017), SDL is also considered pivotal in MOOCs (Bonk, Lee, Reeves, \& Reynolds, 2015; Kop \& Fournier, 2010; Terras \& Ramsay, 2015). However, a variety of studies have stated that learners feel anxious about SDL and expect to have instruction and guidance on SDL at the beginning of courses (Hewitt-Taylor, 2001; Lunyk-Child, Crooks, Ellis, Ofosu, \& Rideout, 2001; Prociuk, 1990). Not surprisingly, facilitation is expected to ensure that students confidently develop the appropriate SDL skills (Kell \& Deursen, 2002; Lunyk-Child et al., 2001).

Along with motivation and self-management, self-monitoring is one of the key elements of SDL (Garrison, 1997). Self-monitoring involves cognitive and metacognitive processes, which include monitoring one's own learning strategies and the ability to think about thinking. For 
example, self-directed learners know how to evaluate their learning and self-reflect. Previous studies argued that self-monitoring can improve students' performance (Chang, 2007; Coleman \& Webber, 2002). In addition, some studies have indicated that teaching self-monitoring skills can benefit learners (e.g., Delclos \& Harrington, 1991; Maag et al., 1992; Malone \& Mastropieri, 1992; Schunk, 1982)

However, as several researchers have pointed out, the instructional design and actual delivery of MOOCs from the perspective of MOOC instructors are significantly underexamined (Margaryan, Bianco, \& Littlejohn, 2015; Ross, Sinclair, Knox, Bayne, \& Macleod, 2014; Watson et al., 2016; Zhu, Sari, \& Lee, 2018); especially lacking is research on instructor perceptions in terms of facilitating student self-monitoring for SDL.

In response, this study examined how instructors design and deliver MOOCs to facilitate learners' self-monitoring skills for SDL. It also explored how different technologies are used to facilitate such self-monitoring. A key purpose is to begin to understand how MOOC instructors put considerations related to facilitating self-monitoring skills into MOOC designs and delivery.

The following research questions guided this study:

1. How do instructors design and deliver MOOCs to facilitate participant self-monitoring skills for SDL?

2. How are technologies used to support participant self-monitoring skills for SDL in MOOCs?

\section{Self-Directed Learning (SDL) and Self-Monitoring}

The theoretical framework used in this study is Garrison's (1997) three-dimensional model of SDL. The framework includes: (1) self-management (task control); (2) self-monitoring (cognitive responsibility); and (3) motivation (entering and task). This manuscript primarily focuses on one critical element of SDL — namely, self-monitoring. As internal self-monitoring alone is not enough to promote cognitive improvement, instructors were encouraged to provide external feedback to support learners' self-monitoring. It is important to point out that Garrison considered self-monitoring to be a prerequisite of SDL (Garrison, 1997).

As an important part of SDL, self-monitoring focuses on learners' skills to track and evaluate their progress towards specific learning goals (Chang, 2007). Self-monitoring involves self-awareness, which might help learners control their learning process and keep them on task. In addition, self-monitoring training can be effective in improving adaptive goal setting and learning. Several empirical studies have shown that students benefit from being taught self-monitoring skills (e.g., Delclos \& Harrington 1991; Maag et al., 1992; Malone \& Mastropieri, 1992; Schunk, 1982). Moreover, Zimmerman (1999) argued that self-monitoring should be strategically planned and implemented.

Using this chain of research as a guide, Zimmerman and Paulsen (1995) proposed four phases for teaching to enhance students' self-monitoring skills. These phases included: (1) baseline self-monitoring, which refers to initial data collection about the academic activity; (2) structured self-monitoring, which means that students conduct self-observation based on a structured monitoring protocol offered by the instructor; (3) independent self-monitoring, in which learners adapt the course-related self-monitoring protocol to their own personal needs; and (4) selfregulated self-monitoring, in which learners develop monitoring protocols on their own. 


\section{SDL and Self-Monitoring in MOOCs}

To date, studies in the emerging field of MOOCs and open education have indicated that students should be self-motivated and self-directed in MOOCs (Kop \& Fournier, 2011; Rohs \& Ganz, 2015). Given that many researchers have demonstrated that SDL is essential to adult education (Brockett \& Hiemstra, 1991; Candy, 1991; Garrison, 1997; Merriam, 2001), and that most MOOC learners are adults (Shah, 2017), SDL is considered an essential element in MOOCs (Bonk et al., 2015; Kop \& Fournier, 2011; Terras \& Ramsay, 2015). Consequently, research interest in SDL in MOOCs has steadily increased (Bonk et al., 2015).

Previous studies on SDL have focused on the general perceptions of SDL from students' perspectives (Bonk et al., 2015; Loizzo, Ertmer, Watson, \& Watson, 2017) as well as the relations between elements of SDL in MOOCs (Beaven et al., 2014; Kop \& Fournier, 2011; Terras \& Ramsay, 2015). For example, Terras and Ramsay (2015) examined MOOCs from a psychological perspective, wherein they alluded to some central aspects of SDL, such as motivation and selfmonitoring.

While the number of universities offering MOOCs is expanding (Shah, 2019), most studies continue to focus on the student's perspective, such as motivation and completion rates (Zhu et al., 2018). Unfortunately, as alluded to earlier, scant research directly investigates the design of MOOCs to facilitate self-monitoring for SDL from the instructor's perspective. Given this gap in the research, the present study examined instructor perceptions and practices related to their facilitation of self-monitoring for SDL in the design of MOOCs.

\section{Methods}

This study adopted a sequential mixed methods design (Creswell \& Plano-Clark, 2017; Fraenkel \& Wallen, 2009), which includes quantitative data collection and analysis followed by qualitative data collection and analysis (Creswell \& Plano-Clark, 2017). The data sources of this study consist of three main elements: (1) an online survey sent to 1,891 MOOC instructors worldwide via SurveyMonkey, of which 1,083 email requests were opened and 198 valid responses were received; (2) in-depth interviews with 22 instructors who volunteered to participate; and (3) detailed course reviews of the MOOCs taught or designed by the 22 interviewees. The use of these different data sources enabled the researchers to triangulate the data (Patton, 1990). In effect, this approach provided a more nuanced understanding of instructors' perceptions related to designing and delivering MOOCs for SDL than solely relying on one data source (Baxter \& Babbie, 2004).

\section{Data Collection}

Online survey. The survey used in this study was adapted from an instrument developed by Fisher and King (2010) and Williamson (2007) to measure student SDL, which, in turn, was based on the conceptual framework of Garrison (1997). It is important to point out that semistructured interviews with four MOOC instructors and a pilot survey with 48 MOOC instructors were conducted to design and develop the survey instrument (Zhu \& Bonk, 2019). The final survey contained a total of 29 questions, including 20 five-point Likert-scale questions, three closed-ended questions about their perceptions of SDL, including self-monitoring in MOOCs, and six questions related to different demographic information of the participants. Among the 20 fivepoint Likert-scale questions, seven were related to self-monitoring strategies, such as learners' 
goal setting, self-evaluation, responsibility of learning, learning belief, and so on. The demographic information covered MOOC instructors' online design and teaching experiences (including MOOC teaching experiences), the number of enrolled students in their most recent MOOCs, and so on.

To test the internal reliability of the survey, a Cronbach's alpha was conducted in SPSS. The Cronbach's alpha for self-monitoring was quite acceptable at 0.76 . To confirm whether the survey questions measured the construct, an exploratory factor analysis (EFA) was conducted in SPSS. The results showed that the survey questions measured each construct well.

MOOC instructor interviews. Based on an extensive literature review, expert feedback, and survey data analysis results, an interview protocol with 12 questions was developed (see Appendix). The participants of the interviews were a subset of the survey sample. They were selected based on both voluntary participation and their answers to the survey questions. The following criteria were utilized to identify and select the interview participants, who value facilitating student SDL. First, survey participants must have volunteered to be interviewed by providing their email information at the end of the survey. Second, the survey responses had to show that these interview participants considered students' SDL skills when designing and delivering MOOCs. Third, respondent mean scores for five-point Likert-scale questions needed to be higher than 2.5. With the previous three criteria, 70 MOOC instructors were selected. Fourth, the country of the MOOC offered, subject areas or topics addressed, previous experience with online or blended learning, prior MOOC teaching experience, MOOC format (i.e., instructor-led with teaching support, instructor-led without teaching support, self-paced, etc.), and MOOC providers or platforms utilized were all considered when selecting interviewees. The goal was to interview MOOC instructors from highly diverse backgrounds in order to better represent instructional practices for facilitating self-monitoring and related SDL skills and competencies in MOOCs.

Using the fourth criterion, $22 \mathrm{MOOC}$ instructors were selected from 70 volunteers for the interviews (see Table 1). It is important to mention that Guest, Bunce, and Johnson (2006) found that saturation occurred within the first 12 interviews in nonprobabilistic sampling interviews. In this study, the researcher found that the data had reached saturation after finishing 22 instructor interviews. As shown in Table 2, the resulting MOOC instructor interviewees were teaching in the United States $(n=9)$, UK $(n=6)$, Australia $(n=3)$, France $(n=1)$, Belgium $(n=1)$, the Netherlands $(n=1)$, and Israel $(n=1)$. For privacy purposes, the names of the interviewees were assigned pseudonyms. 
Table 1

Interviewees’ Demographic Information

\begin{tabular}{|c|c|c|c|c|c|c|c|}
\hline Pseudonym & Country & Subject area & Platform & Gender & No. of $\mathrm{O} / \mathrm{B}$ & No. of $M$ & Mode of the $M$ \\
\hline Lucas & U.S. & Social science & edX & $\mathrm{M}$ & 0 & 1 & I without $\mathrm{T}$ \\
\hline Branden & U.S. & Education & Udacity & M & 0 & 5 or more & Self-paced \\
\hline Logan & U.S. & $\begin{array}{l}\text { Literacy and } \\
\text { language }\end{array}$ & Coursera & M & 5 or more & 5 or more & I with $\mathrm{T}$ \\
\hline Emma & U.S. & $\begin{array}{l}\text { Literacy and } \\
\text { language }\end{array}$ & Coursera & $\mathrm{F}$ & 2 & 1 & Self-paced \\
\hline Jason & U.S. & Science & edX & M & 1 & 1 & I with $\mathrm{T}$ \\
\hline Jackson & U.S. & $\begin{array}{l}\text { Medicine and } \\
\text { health }\end{array}$ & Coursera & M & 5 or more & 1 & Self-paced \\
\hline Samuel & U.S. & Education & FutureLearn & M & 4 & 3 & Self-paced \\
\hline Hannah & U.S. & Education & Blackboard & $\mathrm{F}$ & 5 or more & 1 & I with $\mathrm{T}$ \\
\hline Ashley & U.S. & Education & edX & $\mathrm{F}$ & 0 & 5 or more & I with $\mathrm{T}$ \\
\hline Andrew & UK & Art & FutureLearn & M & 0 & 3 & I with $\mathrm{T}$ \\
\hline Emily & UK & $\begin{array}{l}\text { Medicine and } \\
\text { health }\end{array}$ & FutureLearn & $\mathrm{F}$ & 2 & 2 & I with $\mathrm{T}$ \\
\hline Aiden & UK & Social science & FutureLearn & M & 0 & 1 & Self-paced \\
\hline Henry & UK & Social science & FutureLearn & M & 0 & 1 & Self-paced \\
\hline Joseph & UK & $\begin{array}{l}\text { Medicine and } \\
\text { health }\end{array}$ & FutureLearn & M & 1 & 1 & Self-paced \\
\hline Joshua & UK & $\begin{array}{l}\text { Literacy and } \\
\text { language }\end{array}$ & FutureLearn & M & 2 & 2 & I with $\mathrm{T}$ \\
\hline Mason & Australia & Education & Coursera & M & 5 or more & 1 & I with T \\
\hline Ethan & Australia & Business & Coursera & M & 3 & 1 & I without $\mathrm{T}$ \\
\hline Ben & Australia & Social science & edX & M & 1 & 1 & I with T \\
\hline Paul & France & Science & Coursera & M & 1 & 1 & I with $\mathrm{T}$ \\
\hline Fernando & Belgium & $\begin{array}{l}\text { Research } \\
\text { methods }\end{array}$ & Blackboard & M & 5 or more & 3 & I with $\mathrm{T}$ \\
\hline Jacob & $\begin{array}{l}\text { Netherla } \\
\text { nds }\end{array}$ & Science & Coursera & M & 0 & 1 & I with $\mathrm{T}$ \\
\hline Dylan & Israel & Science & Coursera & M & 5 or more & 3 & I without T \\
\hline
\end{tabular}

Note. No. of $O / B$ refers to the number of online or blended courses participants had designed or taught prior to the design of the MOOCs. No. of $M$ means the number of MOOCs participants had designed or taught. Mode of $M$ refers to the delivery mode of MOOCs. In this column I without $T$ means that the mode of the MOOC is instructor without teaching assistants. $I$ represents instructor. $T$ represents teaching assistants. 
Table 2

Mean Score and Standard Deviation of the Specific Self-Monitoring Skills That the Participants' MOOC Facilitated

\begin{tabular}{llll}
\hline Items & & Mean & SD \\
\hline 1. & Helps the student be in control of his/her learning & 4.15 & 0.55 \\
2. & Helps the student set his/her own learning goals & 3.68 & 0.91 \\
3. & Helps the student evaluate his/her own performance & 3.94 & 0.78 \\
4. & Helps the student be responsible for his/her learning & 4.06 & 0.79 \\
5. & Helps the student be able to focus on a problem & 3.87 & 0.74 \\
6. & $\begin{array}{l}\text { Helps the student be able to find out information related to } \\
\text { learning content for him/herself }\end{array}$ & 4.02 & 0.70 \\
7. & $\begin{array}{l}\text { Helps the student have high beliefs in his/her abilities of } \\
\text { learning }\end{array}$ & 3.73 & 0.74 \\
\hline
\end{tabular}

Before the interview, the researcher sent the interview protocol to interviewees to better prepare them for it. In addition, the researcher reviewed each interviewee's MOOC to be familiar with the course and intelligently support the interview conversation. The interview data-collection process lasted more than two months. Interviews were conducted via Zoom, an encrypted videoconferencing tool. Each interview lasted around 30-60 minutes, with the interview time across the 22 interviewees totaling 828 minutes. On average, each interview lasted nearly 38 minutes. The data reached a saturation point after 22 interviews, as there was limited new information identified at that point of the interview process (Creswell \& Plano-Clark, 2017; Merriam, 1988, 2009). Thus, it was decided that no additional interview invitations were necessary.

Several research steps were followed to enhance the quality of this study. For example, the interviews were video recorded and transcribed verbatim by the researcher immediately after each interview. To better inform and focus the researchers, initial data analysis was conducted after each interview to inform the following interview. As a means of promoting validity, the researchers conducted member checking with interviewees to confirm the accuracy of the transcripts. Ten of the interviewees provided detailed revision (e.g., misspelling corrections), while 12 replied without revision but claimed that the transcript was accurate. As supplemental materials, two participants shared their research papers on MOOC-related teaching with the researcher. In order to track and reflect on the process, the researcher maintained a research log to keep notes of the interview process. In addition, to solicit participants, a \$20 Amazon gift card was provided to all the interviewees to compensate for their interview and member-checking time. 
Document analysis. The documents for analysis were the MOOCs designed or taught by the interviewees. In fact, the researcher analyzed documents such as learning resources, activities, and assessments provided in MOOCs both before and after the instructor interview. The MOOCs provided by those interviewees were reviewed for triangulation of the data to enhance the validity of the study.

\section{Data Analysis}

The survey used a five-point Likert scale to measure instructors' perceptions of selfmonitoring in MOOCs. Consequently, the data was analyzed using descriptive statistics, such as mean, frequency, and percentage, in SPSS and Excel.

In terms of the qualitative data, a classical content analysis, which counts the number of times each code occurs, and a constant comparison analysis were conducted in NVivo 12. The researcher's verbatim transcription was implemented for coding. To promote validity, first-level member checking was conducted, which means that transcripts were sent back to the 22 interviewees for a member check to ensure the accuracy of the transcripts. Following member checking, the researchers utilized classical content analyses to abductively analyze data (Leech \& Onwuegbuzie, 2007). The unit of analysis in this study was the meaning unit.

To perform an abductive content analysis, the lead researcher had a general self-monitoring concept and research questions in mind. Then, she read through the entire set of data, chunked the data into smaller meaningful parts, labeled each chunk with a code, and compared each new chunk of data with previous descriptions; any similar chunks were labeled with the same code. Once all the data had been coded, the lead researcher grouped the codes by similarity to identify themes. In general, the researcher read through the transcripts and conducted open coding followed by methods recommended by Haney, Russell, Gulek, and Fierros (1998).

\section{Results}

\section{Survey Participant Disciplines and Online Experience}

Survey participants $(n=198)$ were from more than 20 different disciplines in this study. The subjects that MOOC instructor participants taught included social science $(22.7 \%)$, medicine and health (13.6\%), language and literacy (12.1\%), business and management $(11.1 \%)$, art and humanities $(7.1 \%)$, physical science $(6.6 \%)$, computer science $(6.1 \%)$, data science $(6.1 \%)$, biology (5.1), mathematics (4.5\%), engineering (2.5\%), and other areas $(2.5 \%)$.

Interestingly, 102 out of 198 participants $(51.5 \%)$ had no online or blended course design and teaching experience prior to designing their first MOOC (see Figure 1). At the other end of the spectrum, 37 participants $(18.6 \%)$ designed or taught five or more online or blended courses prior to designing their initial MOOC. 


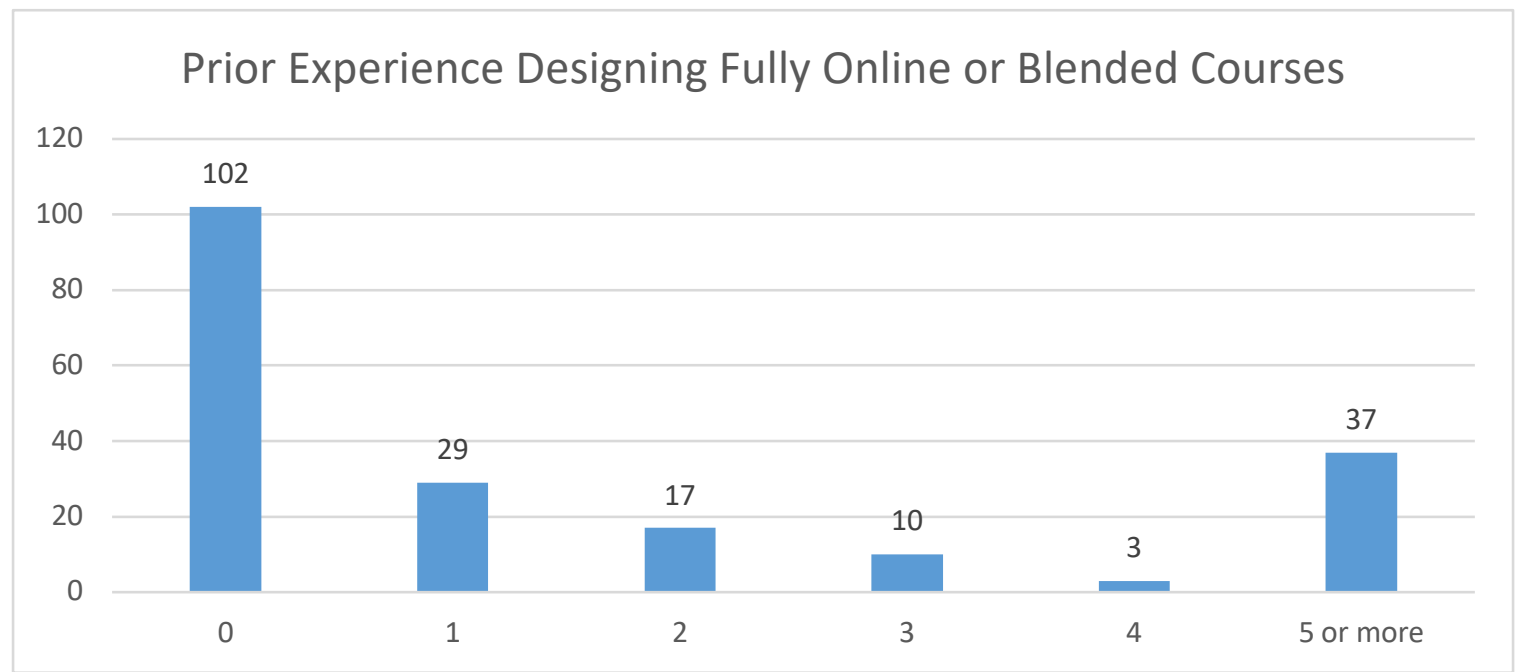

Figure 1. Instructor experience related to designing fully online or blended courses prior to designing their first MOOC.

With regard to MOOC design and teaching experience, $59.6 \%$ participants $(n=118)$ had designed or taught only one MOOC (see Figure 2$)$. On the other hand, 9.6\% participants $(n=19)$ had previously designed or taught five or more MOOCs.

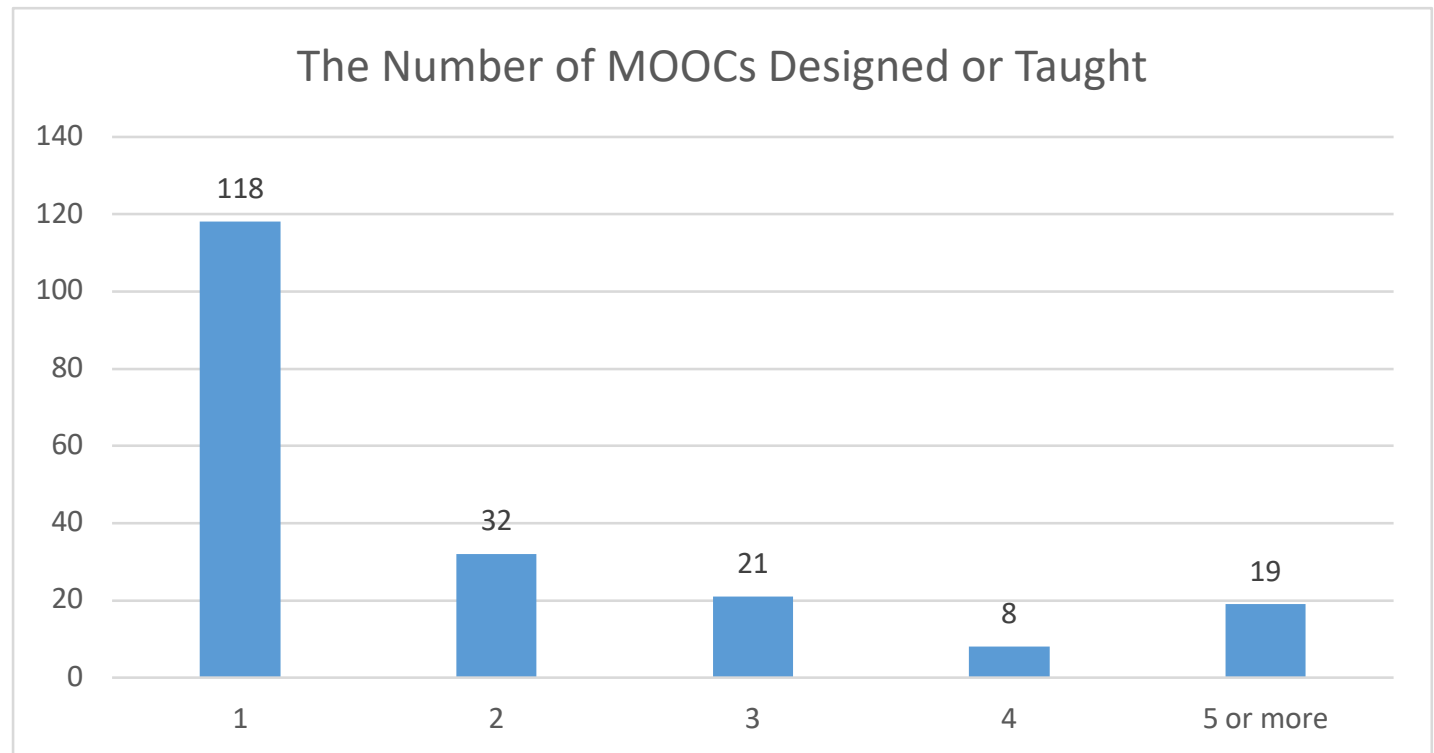

Figure 2. The number of MOOCs that the instructor had designed or taught.

In terms of delivery modes of survey participants' MOOCs, $42.9 \%$ of their MOOCs $(n=$ 85 ) were self-paced. In line with our previous studies, which found between $35 \%$ and $43 \%$ of MOOCs being instructor led with teaching assistant, moderator, or tutor support (Bonk et al., 2018; Zhu, Bonk, \& Sari, 2018), 33.3\% MOOCs $(n=66)$ were led by instructors with such additional support, followed by 29 MOOCs with instructor led without TA support (14.6\%; see Figure 3). 


\section{Delivery Modes}

Instructor led with teaching assistants, moderators, and/or tutor support

Instructor led with no additional teaching support

Other (Please describe):

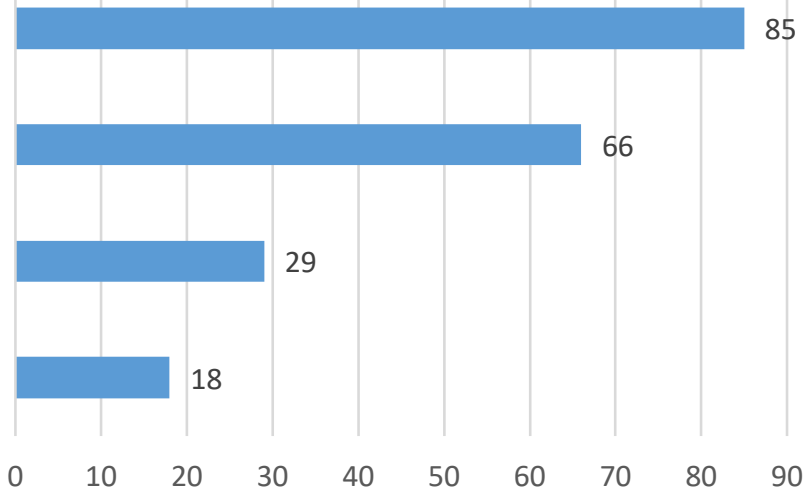

Figure 3. Survey participants' MOOC delivery format.

\section{Research Question 1: How Do Instructors Design and Deliver MOOCS to Facilitate Participant Self-Monitoring Skills for SDL?}

\section{Survey Results}

Instructors $(n=198)$ ranked on a scale of 1 (strongly disagree) to 5 (strongly agree) whether the design and delivery of their MOOC helps students to develop SDL skills in terms of various components. For instance, the majority of MOOC instructors surveyed reported that the design and delivery of their MOOCs helped students to be more in control their learning. Specifically, $33.3 \%$ of MOOC instructors $(n=66)$ chose strongly agree and $57.6 \%(n=114)$ reported agree. Only three selected disagree or strongly disagree.

In terms of the statement that "the MOOC helps students set their learning goals," 46 out of $198(23.2 \%)$ MOOC instructors reported that they strongly agreed, while 99 instructors $(50.0 \%)$ reported that they agreed with the statement (see Figure 4). Twenty-one percent of MOOC instructors $(n=42)$ selected neutral. The remaining $11(5.6 \%)$ instructors reported that they disagreed or strongly disagreed. 


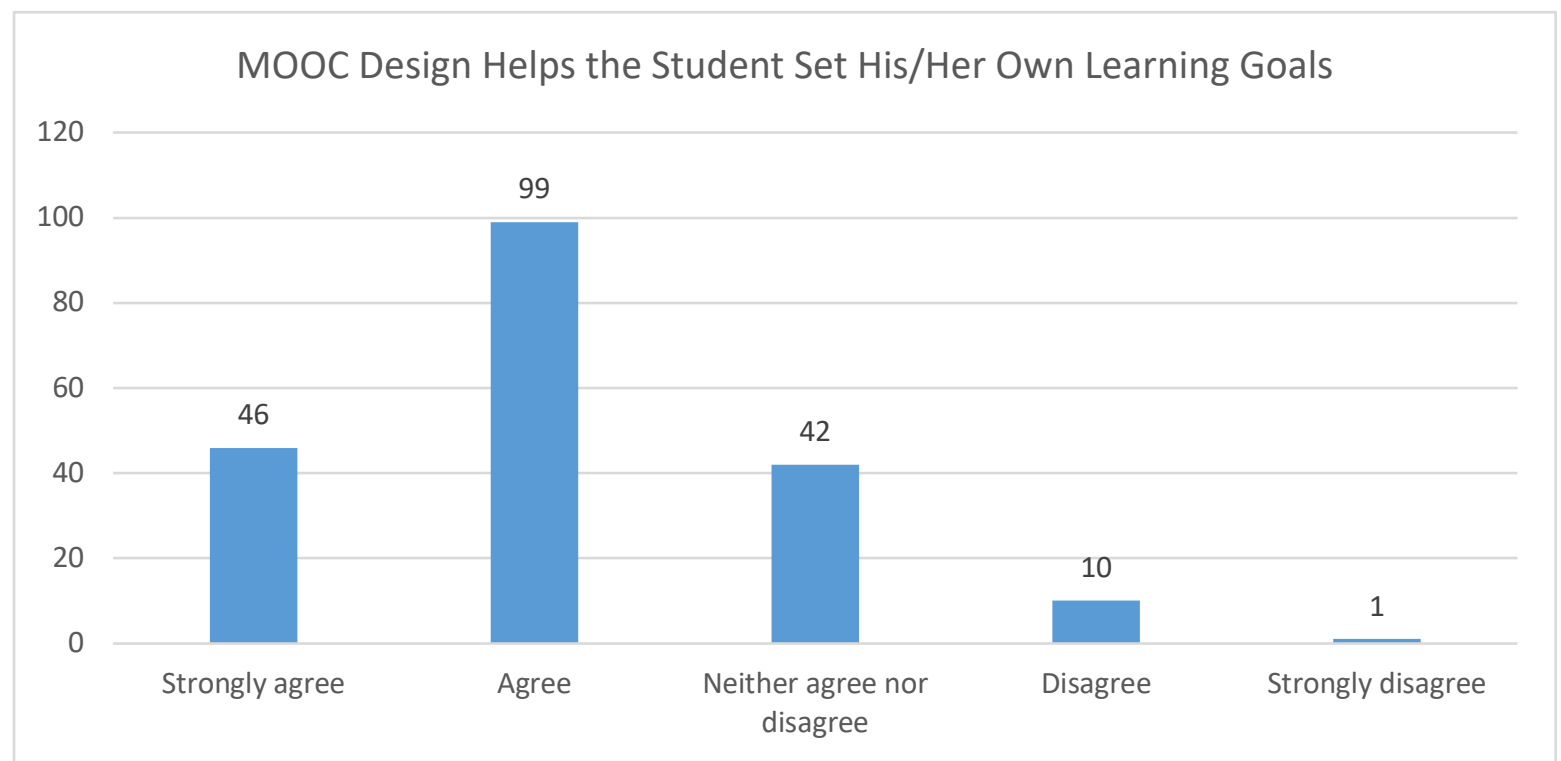

Figure 4. MOOC design helps the student set his/her own learning goals $(n=198)$.

Over $80 \%$ of MOOC instructors $(n=160)$ agreed or strongly agreed that their MOOCs help students evaluate their own performance (see Figure 5). Twenty-eight MOOC instructors (14.1\%) selected neutral. The other $10 \mathrm{MOOC}$ instructor respondents (i.e., 5.1\%) indicated that they disagreed with that statement.

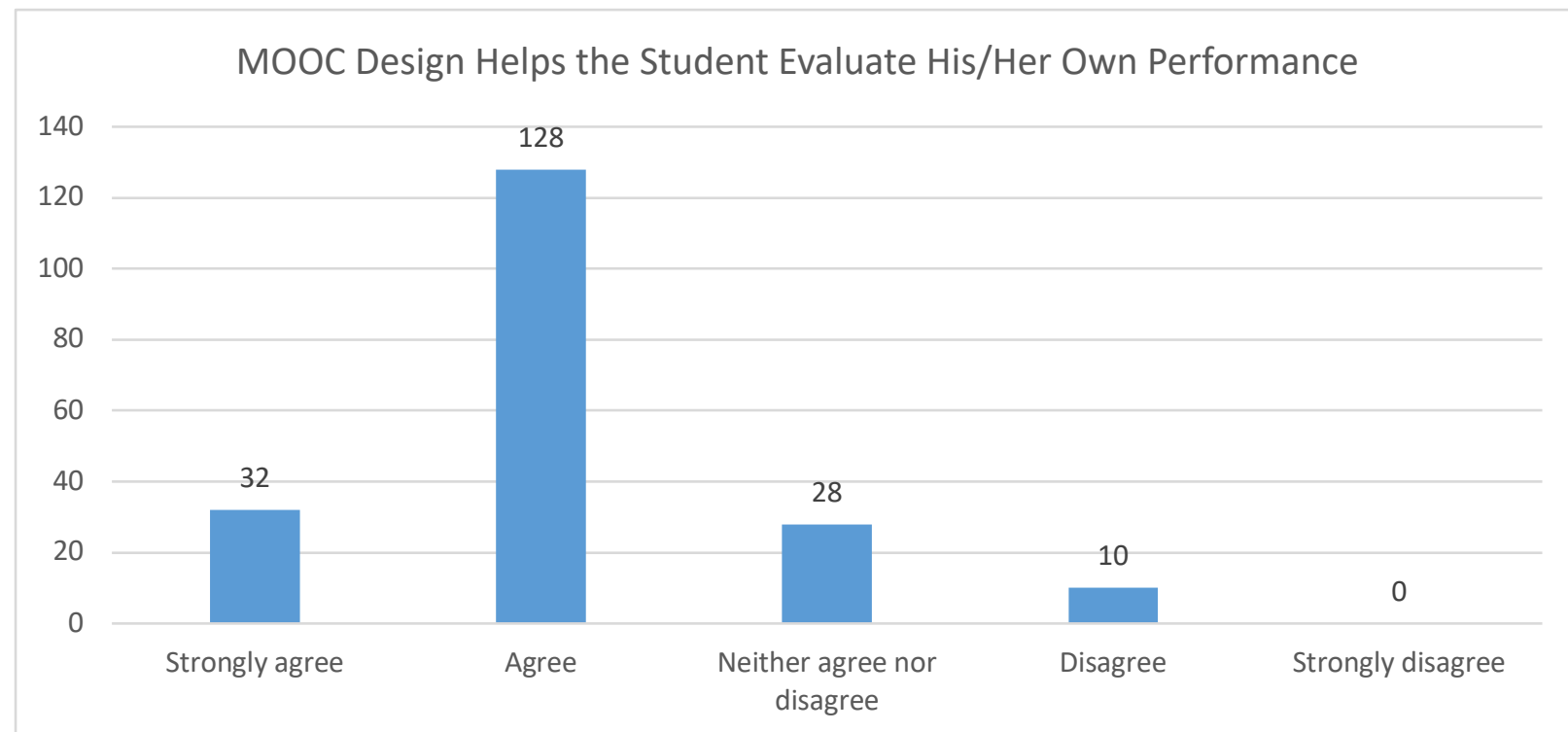

Figure 5. MOOC design helps the student evaluate his/her own performance $(n=198)$.

Regarding the statement "MOOC design helps the student be responsible for his/her learning," a majority of MOOC instructors $(88.4 \% ; n=175)$ reported that they strongly agreed or agreed with this statement (see Figure 6). Twenty-one MOOC instructors (10.6\%) selected neutral. As a sign of the importance of SDL in MOOCs, just one each selected disagree or strongly disagree. 


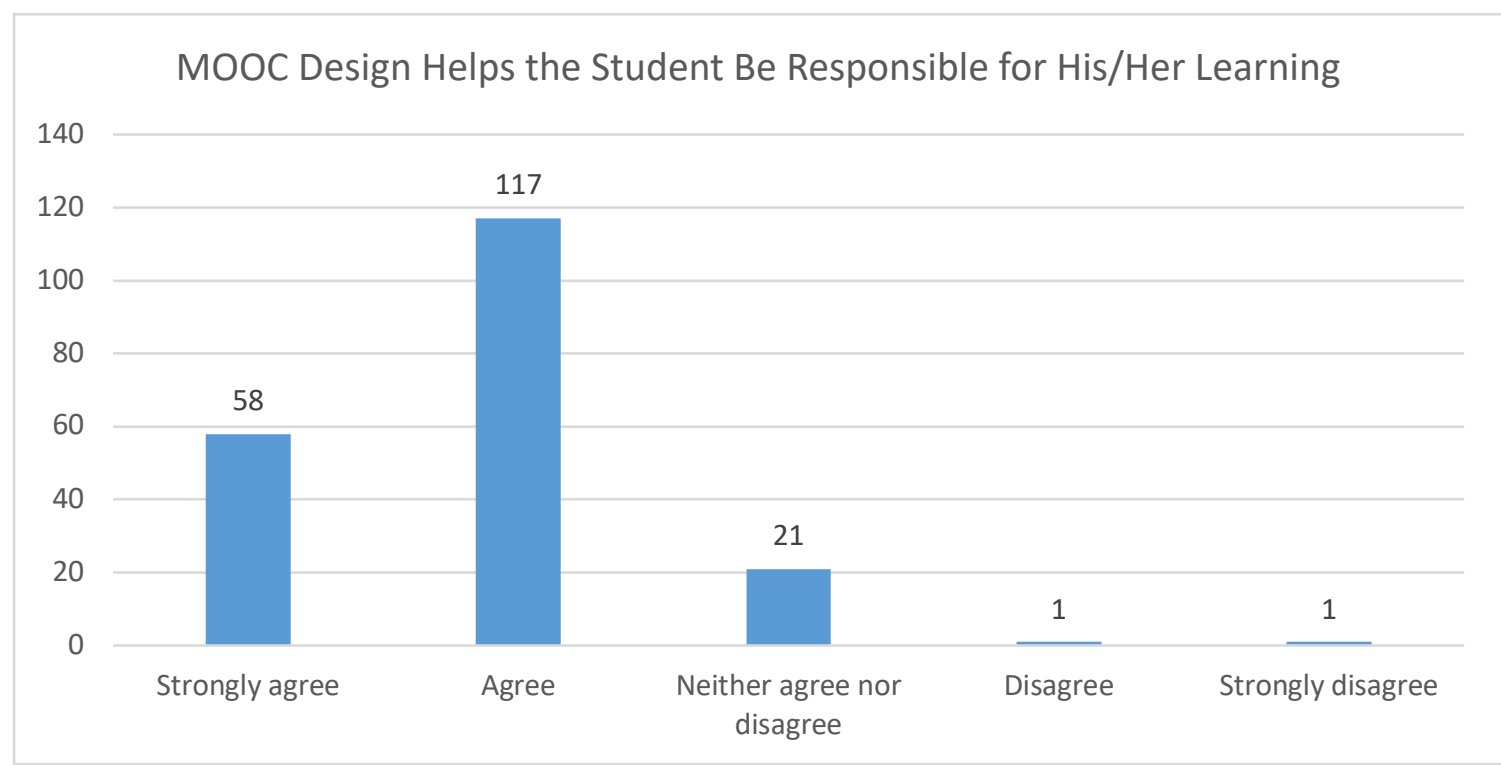

Figure 6. MOOC design helps the student be responsible for his/her learning $(n=198)$.

In terms of helping students focus on a problem, $74.2 \%$ of MOOC instructors $(n=147)$ agreed or strongly agreed with the statement. And 46 out of 198 MOOC instructors $(23.2 \%)$ held a neutral attitude. The other five respondents $(2.5 \%)$ reported that they disagreed or strongly disagreed that it "helps the student be able to focus on a problem."

Regarding the statement that "the MOOC design helps the student be able to find information related to learning content for him/herself," $23.7 \%$ of MOOC instructor respondents $(n=47)$ strongly agreed with that statement, and $47.5 \%(n=94)$ agreed with it. In addition, 44 out of 198 MOOC instructors (22.2\%) responded neutrally to that statement. The rest of the respondents $(6.6 \% ; n=13)$ reported strongly disagree or disagree.

Last but not least, for the statement "the MOOC helps the student have high beliefs in his/her abilities of learning," $41.9 \%(n=83)$ agreed with the statement, and another $18.2 \%$ of the MOOC instructor respondents $(n=36)$ strongly agreed. Perhaps somewhat more telling, 35.4\% MOOC instructors $(n=70)$ neither agreed nor disagreed with the statement. The remaining nine instructors $(4.5 \%)$ reported that they strongly disagreed or disagreed with the statement.

\section{Interview Results}

During the interviews, MOOC instructors reported that they facilitated students' selfmonitoring in a range of ways, from helping students with internal feedback to providing external feedback (see Table 3 for details). Of course, external feedback and internal feedback are intertwined. Students' internal feedback includes cognitive and metacognitive processes. Cognitive processing involves self-observation, self-judgment, and self-reaction. Metacognitive processing is related to reflection and thinking critically. External feedback is provided not only by the MOOC instructors but also by their teaching assistants as well as students' peers in the MOOC. 


\section{Table 3}

Strategies to Facilitate Students’ Self-Monitoring

\begin{tabular}{|c|c|c|}
\hline \multicolumn{2}{|l|}{ Strategies } & Quotations \\
\hline \multicolumn{3}{|c|}{ Internal feedback } \\
\hline \multirow[t]{5}{*}{ Cognition } & Quiz & $\begin{array}{l}\text { In every module, there is a self-assessment quiz that they can take as many times as } \\
\text { they want to demonstrate mastery. So that helps them self-assess whether they're } \\
\text { getting the content that I want them to learn. (Hannah) }\end{array}$ \\
\hline & Tutorials & $\begin{array}{l}\text { I think that's actually a very useful skill in itself for them to learn. And it's really } \\
\text { funny, because we think nowadays it's } 2018 \text {. And, of course, all school teachers } \\
\text { know how to set up a website, and how to download an image, and put it in a Web } \\
\text { page, and how to edit it. Oh, yes, of course, they don't. They don't have a clue.... } \\
\text { It's a sort of bonus little skills for people. (Mason) }\end{array}$ \\
\hline & $\begin{array}{l}\text { Learning } \\
\text { strategies }\end{array}$ & $\begin{array}{l}\text { We had one video right at the beginning. Students had access. That gave people } \\
\text { advice about learning in a MOOC. (Lucas) }\end{array}$ \\
\hline & $\begin{array}{l}\text { Learning } \\
\text { aids }\end{array}$ & $\begin{array}{l}\text { I walk them through in the first module in a sequential way in the video, where I'm } \\
\text { showing them the course. So all of these videos walk them through all of the } \\
\text { different elements of the course. ... So I really try to be as organized and scaffold it } \\
\text { as early as possible, so they can be successful on all those task oriented type things. } \\
\text { (Hannah) }\end{array}$ \\
\hline & Modeling & $\begin{array}{l}\text { Because we're teaching people how to teach. We have to do a lot of strategies that } \\
\text { help teachers. ... Like, we have to model the behavior a lot. (Logan) }\end{array}$ \\
\hline \multirow[t]{2}{*}{ Metacognition } & $\begin{array}{l}\text { Reflection } \\
\text { questions }\end{array}$ & $\begin{array}{l}\text { We introduced kind of moments that video was stopped and there was a question. } \\
\text { The student had to think of it a bit. Sometimes it was kind of a rhetorical question. } \\
\text { There wasn't even [an] answer required. But it was just a pause for a while to let } \\
\text { the student reflect. (Jacob) }\end{array}$ \\
\hline & $\begin{array}{l}\text { Learning } \\
\text { community }\end{array}$ & $\begin{array}{l}\text { We've got a Facebook community of teachers who teach through the medium of } \\
\text { English to international audiences. And that's another place for conversation and } \\
\text { networking. So people start to realize what they want to achieve, and what they } \\
\text { want to improve, and where they want to focus on the course. And they can } \\
\text { communicate more effectively on the MOOC because they are networking outside. } \\
\text { So that sometimes happens. (Joshua) }\end{array}$ \\
\hline \multicolumn{3}{|c|}{ External feedback } \\
\hline Instructors & & $\begin{array}{l}\text { I think it's really important to keep students both in the MOOC and on campus in a } \\
\text { feedback loop. "OK, you are learning. You probably don't even know you're } \\
\text { learning some of these things. But, you have picked them up." It is important to } \\
\text { keep having those conversations with them, [and] having that feedback loop both } \\
\text { through the panels and the lectures. (Joseph) }\end{array}$ \\
\hline \multicolumn{2}{|c|}{ Teaching assistants (TAs) } & $\begin{array}{l}\text { There is a discussion board. In [the] discussion board, I have an assistant, who } \\
\text { monitored a discussion board. She reviews all the discussion items on a regular } \\
\text { basis each week. She answers the questions that she is familiar with. If she's not, } \\
\text { then she ask[s] me. And I write her responses. And she posts in her own language. } \\
\text { (Jackson) }\end{array}$ \\
\hline \multicolumn{2}{|l|}{ Peers } & $\begin{array}{l}\text { The way assessment works for our assignments, there are instructions. We asked } \\
\text { learners to submit in the forums. And then we have guidelines for peer feedback. } \\
\text { Again, all of this is on the forum system. So people are providing feedback to their } \\
\text { peers in the forums. (Ashley) }\end{array}$ \\
\hline
\end{tabular}


Facilitate student internal feedback. MOOC instructors help student self-monitoring in terms of both cognitive and metacognitive processes. To help students' cognitive learning processes, MOOC instructors indicated that they usually provided quizzes for self-assessment, tutorials on technology use, navigational aids for the course, supplemental resources, and instructional modeling. They also supported effective learning strategies with their instructional scaffolds, feedback, and suggestions, such as the best sequences for studying the related topics. Scholars claim that self-assessment helps students reflect on their learning and achievement (Pintrich \& Zusho, 2002; Zimmerman \& Schunk, 2001). In this study, 13 out of 22 MOOC instructors mentioned that they used quizzes or tests to help student self-assessment. Jacob, a science instructor from the Netherlands, stated the following:

Well, I think there was always a few test questions in between. Indeed, they were really self-monitoring questions because you did not to pass them or so to go on. There is really self-monitoring questions just to see if you get the highlights from either the video or the reading material that was presented. I think that helps [the] student at least to do the selfmonitoring part. ... We introduced kind of moments that video was stopped and there was a question. The student had to think of it a bit. Sometimes it was kind of a rhetorical question. There wasn't even [an] answer required. ... And the question was then to let students think about how you think this would work or something like that.

Besides quizzes for self-assessment, MOOC instructors provided tutorials on technology use to support students' cognitive learning processes. For instance, Mason, an education instructor from Australia, stated that he made a tutorial on how to use a tool (i.e., WordPress) to help students' learning in the MOOC. In addition, MOOC instructors provided learning strategies and tips to students. One example is that a medicine and health instructor, Joseph, provided discussion participation tips. As he detailed,

I told people that we cover a wide range of topics. It is really up to you what you want to concentrate on most. Do not try to read every post. Do not try to respond [to] every post. Because you spend 4-5 hours a week. You have to make some choice[s]. I think that give[s] them advice on learning strategies.

MOOC instructors also reported that they provided navigational aids for students learning in MOOCs. For instance, Hannah, an education instructor from the United States, provided scaffolding to students to help them focus on tasks. For instance, she noted that:

We also have a visual map, too. Just to give them different ways to look at the topics that we cover for each module. And then I get them some common terminology in the course in case they are brand new and don't know some of these terms and what the expectations are as participants.

Henry made learning resources available to help students' cognitive processes. As he observed, "I think we try to get the resources they can refer to. If you get stuck, they can come back to the previous videos." Logan, a language and literacy instructor from the United States, used a different strategy to help students' cognitive processes. The students in his course were mainly teachers who were teaching or would teach English as a foreign language (EFL) learners. In order to help EFL teachers, he modeled teaching approaches to his students, which allowed them to believe that it was easy to achieve their goals. 
In addition to the strategies used to facilitate students' cognitive processes, MOOC instructors also paid attention to facilitating students' metacognitive processes. In terms of metacognition, the interviewees indicated that they encouraged students to reflect and think critically by providing reflection questions and opportunities to reflect. They also attempted to build learning communities. Five out of 22 MOOC instructors had self-reflection questions embedded in the MOOC to encourage students' self-reflection. A social science instructor from Australia, Ben, observed the following:

In terms of self-monitoring, I think students often find it very difficult to self-evaluate and self-recognize. As I mentioned earlier, I've got three modules. At the end of each module, I have those questions that I talked about what you have learned now, and what you are not sure about, and what you need more information about.

However, the language instructor from the UK, Joshua, encouraged students to reflect on their previous learning through watching summary videos before they moved on. As he noted,

At the end of each week, we've made a video, a live video, to try and draw attention to what different people were saying. Because we could notice patterns of what people were saying ... we could draw attention to particular participant, and say, "This person is doing this. That sounds pretty interesting. This other person is doing that. And that sounds really interesting." We were hoping to draw people's attention to the bigger trends that [are] happening. Maybe they don't notice. They do the step. And then they go to the next step. They forget what came before. So we were trying to encourage people to go back and discuss the basics before they moved on.

Another strategy that MOOC instructors reported that they used is to create a learning community to help students' reflection and have conversations with peers. The learning community can help students communicate with each other effectively concerning course tasks. As an example, Joshua from the UK stated that he created a Facebook page for students to interact and communicate with each other. This concurs with the previous studies, such as Sze-Yeng and Hussain (2010) and Fischer and Sugimoto (2006). Fischer and Sugimoto (2016) indicated that learning communities can transfer the isolated image of the reflective practitioner (Schon, 1983) to reflective communities (Fischer, 2005) for self-directed learning.

Provide external feedback to help students' self-monitoring. Besides helping students' internal feedback processes, MOOC instructors also mentioned that they provided external feedback to help student self-monitoring. The external feedback was usually from MOOC instructors, teaching assistants (TAs), and student peers.

Six out of 22 MOOC instructors mentioned that they or their TAs provided feedback to students to assist in monitoring their learning. In addition, Joseph from the UK held synchronous meetings with students in Google Hangouts to provide feedback to them. One example that he mentioned was the following:

I think, one of the things, which hopefully, help students to reflect and learn meaningfully was the synchronously meeting using Google Hangout[s] at the end of Week Two, Four, and Six. We encourage students to post questions or talking points. And my colleague and I respond to some points. 
Given that 12 out of 22 MOOC instructors had TAs in their MOOCs, the TAs helped provide feedback to students. For instance, the science instructor, Jason, had his graduate student as his TA to provide feedback to students on a discussion board. He observed that,

People would write in questions or comments or whatever. And, I wasn't managing the discussion board in any of the versions of MOOCs that we offered. I had my graduate student, Josh. He's closer to the age of most of the learners. He could develop conversations that I probably didn't have the social skills to develop. ... And in our case, it was Nate who have been very, very, very closely involved in the development of the MOOC. Nate knew where the strong and weak points of the MOOC were, and could answer people's questions about not only sharks, but what they [were] supposed to take away from this.

Thirteen out of 22 MOOC instructors talked about how they use peer assessment to help students' self-monitoring. They highlighted that self-monitoring is a social process, which involves interaction with others. Peer assessment was considered beneficial for both the learners who provided the feedback and the learners who received feedback (Barak \& Rafaeli, 2004; Dochy, Segers, \& Sluijsmans, 1999). In peer assessment, students not only get other students' feedback but also help them self-reflect through providing feedback to peers. For example, a literacy and language instructor, Emma, used peer assessment in her MOOC to motivate students and help them with self-reflection. As Emma observed,

We also put in peer evaluation because they thought that the interaction between students would motivate them. We give a very, very basic syllabus because we don't know what the educational background and the levels of the students [are]. ... Maybe five different key points enable them to evaluate other students on assignment[s]. Just to make it accessible, but to also keep them engaged as other people are looking at their work. But they're also looking at other work to see like what's a more advanced learner doing with this assignment, and how you can be near that or learn from them.

Suggestions to help student self-monitoring. Different MOOC instructors held different opinions on helping students with self-monitoring, such as through assessment, facilitation with discussion, providing diverse materials, and adaptive learning systems. Eight out of 22 MOOC instructors provided suggestions on using assessment for self-monitoring. Emily, a medicine and health instructor from the UK, pointed to the value of embedding short quizzes with immediate feedback. As she suggested, "Take opportunities to allow students to easily assess their own learning, quizzes, and tasks that they can get immediate feedback. I think that is very important."

Similarly, Jacob from the Netherlands also thought some simple questions are helpful. However, he emphasized the quizzes embedded in videos for self-monitoring and motivation. His experience with such types of quizzing is shown in the following quote:

And one feature I really like is that you could [i.e., foster self-monitoring], if you had built in questions in the videos. The video stopped, the student was forced to think [for] him or herself before the video proceeded. I think it helps because if you just passively basically watch this video it's very easy to stop thinking. And I think with built in video questions, that keeps them alert. ... I mean that gives kinds of motivation and self-monitor[ing].

However, Mason from Australia pointed out that using diverse ways to demonstrate students' learning is more important than just multiple-choice questions. He stated that, 
There are things you're going to assess. But much more important is that the way that the student shows [that] they're learning, right? So you need to make those outcomes related to real life. It's not good enough to just have multiple choice questions that confirm whether or not they learn some facts that might be necessary for a little part of the course. ... But people need to go out and make something. They need to go out and have a chance to think and share their ideas. And so that's very, very important for assessment design I think.

Besides self-assessment mentioned above, Henry, a social science instructor from the UK, suggested having peer assessment for practical reasons. He observed, "We have people write a paragraph in English. I may have them peer review it. Because this course has so many people, we cannot mark with these assessments. So we did peer review."

Fernando, a research methods instructor from Belgium, emphasized that instructors should facilitate discussion. Per Fernando, "You've got to use the possibilities that come with the MOOC environment and really facilitate that MOOC conversation." Similarly, Henry, a social science instructor who teaches history, stated,

We find the MOOCs work best when they're very actively mentored. If you use the social learning platform that relies on discussions. Discussions flow better if the learners have a sense that the educators are in the room with them. So when my MOOC was running, I $\operatorname{spen}[t]$ ten minutes every day to answer a couple of questions. That's enough to let people see that I'm in there. I am listening. I'm kind of following along. I got 2 or 3 master's and $\mathrm{PhD}$ students that we pay to do six hours a week of being in there and commenting on the stuff. That really helps. We got a lot of very positive feedback on that from people saying they've noticed that the MOOC is really well supported by the university.

In addition to assessment and feedback comments and ideas mentioned above, MOOC instructors suggested providing diverse and appropriate learning materials to students. For instance, a business instructor from Australia, Ethan, stated that,

I had appropriate readings and resources to go through. They were supplemented with industry reports as well. So, there was a whole lot of different levels of content. And I think that was pretty important to give that a variety of some things such as something that is very simple, and something that is a bit more complicated.

\section{MOOC Review Results}

Through reviewing 22 MOOCs, we found that the design and delivery of MOOCs facilitated students' self-monitoring through their internal cognitive and metacognitive processes as well as various external support structures and mechanisms. The facilitation with cognitive processes included quizzes, providing introductions, aids to help with course navigation, progress bars, and optional resources. To help metacognitive processes, these MOOC instructors encouraged students to share their thoughts in discussion forums and attempted to build a sense of a learning community.

Facilitate student self-monitoring. As mentioned before, these MOOC instructors provided practice quizzes with immediate feedback to enable students to assess their own learning. Whereas some of the quizzes were independent tasks, others were embedded in MOOC videos (see Figure 7 for an example). As shown in Figure 8, after students took a quiz, they could obtain immediate system-generated feedback and brief comments. 
Designing MOOCs to Facilitate Participant Self-Monitoring for Self-Directed Learning

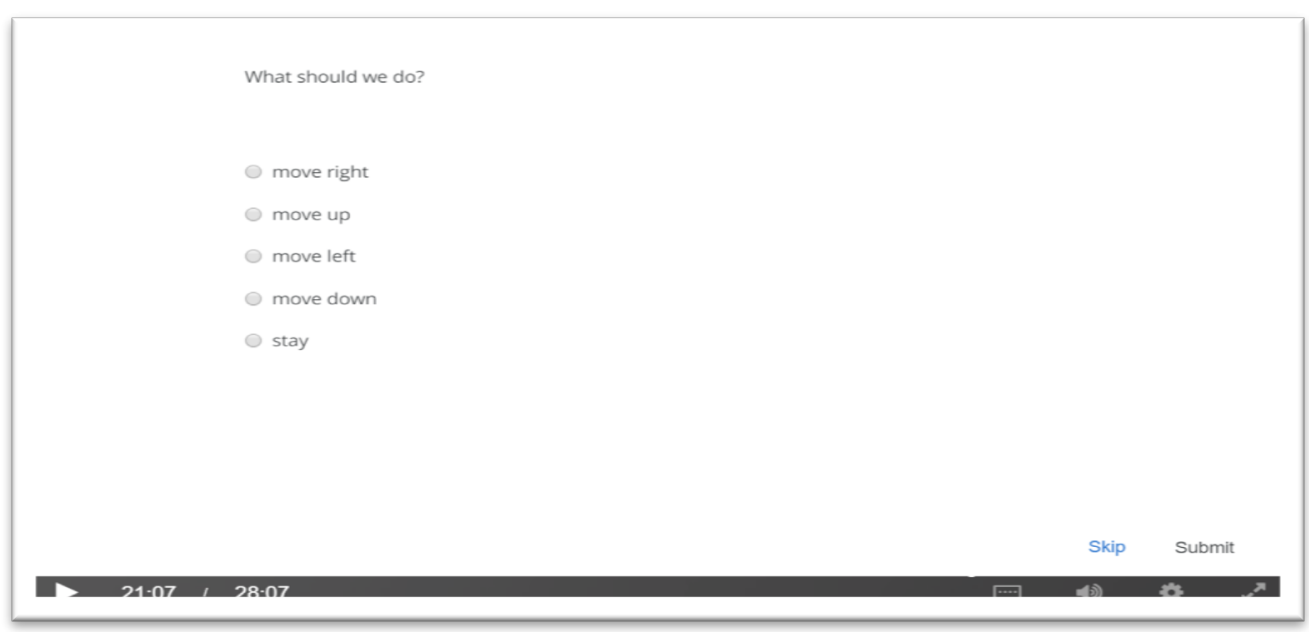

Figure 7. Example of quizzes embedded in videos.
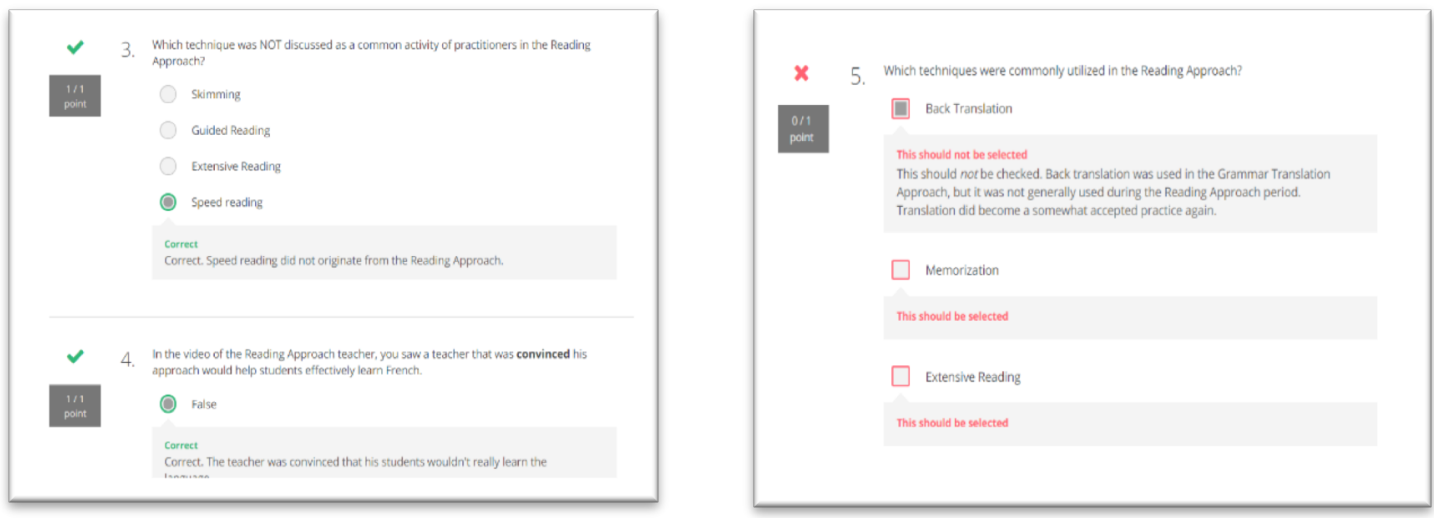

Figure 8. Example of immediate feedback in a MOOC.

In addition, MOOCs provide introductory videos to the course and navigational aids to journey through them. Providing clear navigation can reduce students' cognitive load on items unrelated to the topic, which enables participants to focus more time on content-related cognitive processes (see Figure 9).

Dear students, welcome to the first week of

Here are a few details about the structure of the course: For each week, a lecture and a tutorial videos will be presented, together with a downloadable copy of all the relevant python programs mentioned in the videos. Some in-video questions and practice quizzes will help you to review the material, with no effect on the final grade. A mandatory peer-graded assignment is also present, for weeks from 1 to 9 , and it will expand on the lectures' topics, letting you reach a deeper understanding. The nine peer-graded assignments will make up for $50 \%$ of the grade, while the other half will come from a final exam, after the last lecture.

$\wedge$ Less

Figure 9. Introduction and navigation of a MOOC. 
Besides motivating students, a progress bar helps learners to monitor their learning process and adopt appropriate learning strategies. Additionally, MOOC instructors provided optional reading materials to students (see Figure 10). When this occurs, students can monitor their own learning status and choose readings appropriate to their knowledge level to read.

Reading: BASIC: A Blanket Around the Earth $10 \mathrm{~min}$

Reading: ADVANCED: A Blanket Around the Earth $10 \mathrm{~min}$

Figure 10. Introduction and navigation of a MOOC.

To help with metacognitive processing, the MOOC instructors encouraged students to reflect and share their thoughts in discussion forums and through building learning communities (see Figure 11).

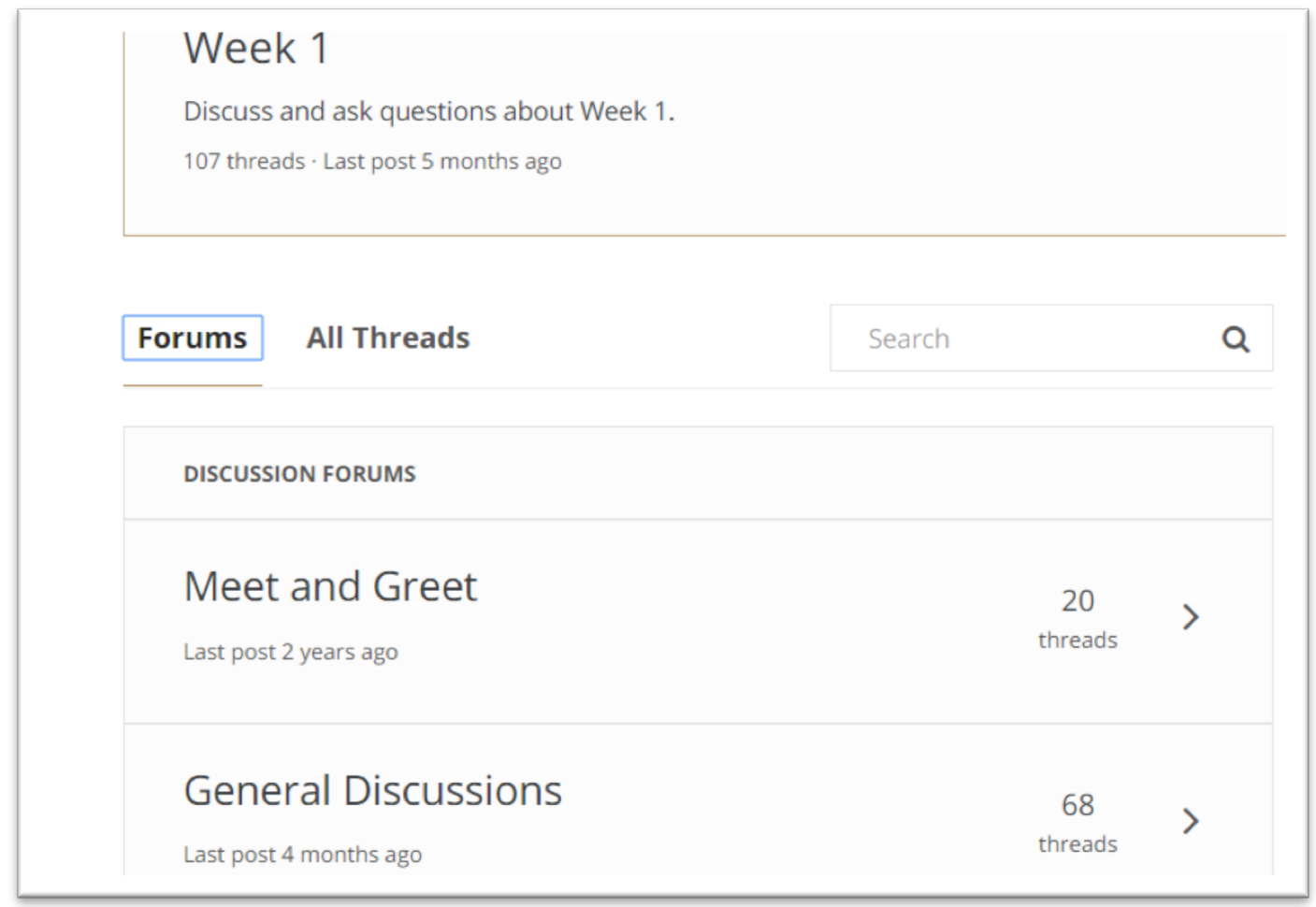

Figure 11. Discussion forum for learning community.

Provide external feedback to help students' self-monitoring. Aligned with interview results, this research investigation found that the MOOC instructors and TAs facilitated discussion forums. In these forums, they addressed students' questions and encouraged peers to provide feedback to each other (see Figure 12). By obtaining such external feedback, students might better monitor their own learning. 


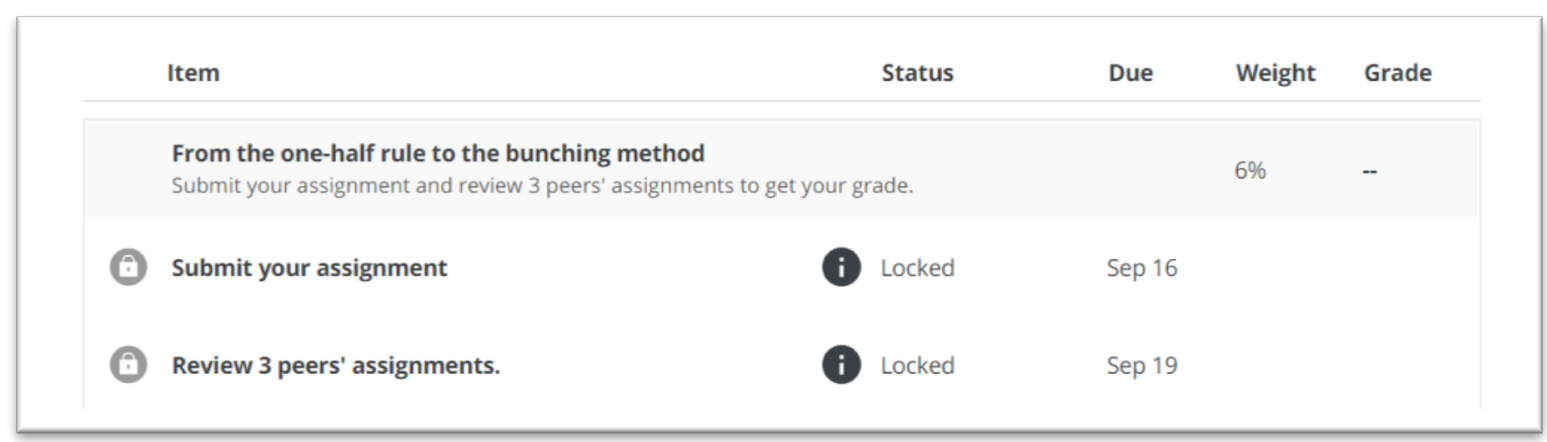

Figure 12. Peer assessment in MOOCs.

\section{Research Question 2: How Are Technologies Used to Support Students' Self-Monitoring Skills for SDL in MOOCs?}

Technologies play an important role in online learning environments, including MOOCs. Some technologies, such as a learning management system (LMS), can provide the learning context (Puzziferro, 2008) or serve as the communication tools (e.g., Google Hangouts). To facilitate student self-monitoring, MOOC instructors mentioned that a variety of technologies were used to facilitate students' self-monitoring, including synchronous communication technologies, asynchronous communication technologies, and feedback tools.

\section{Synchronous Communication Technologies}

MOOC instructors in this study revealed that they used synchronous technologies, such as Google Hangouts and YouTube Live, to host meetings with students. These instructors thought that using synchronous technologies could provide enhanced opportunities for social interaction between instructors and students, which might foster students' self-monitoring. For example, Hannah used Google Hangouts to conduct a weekly broadcast to connect with students as well as address their questions. Along these same lines, another MOOC instructor, Ashley, used YouTube Live to stream her lectures online and answer participant questions. As she noted,

These are live events that we do us[ing] YouTube Live. I don't know if you've ever seen that. So, basically, the instructor talks and our learners can just go to YouTube link, and see what the instructors are saying. And also they can ask questions.

\section{Asynchronous Communication Technologies}

MOOC instructors reported that they used asynchronous communication technologies, such as discussion forums, Blog, Padlet, Slackbot, social media, Today's Meet, and Discourse (a discussion platform), to connect with MOOC students and attempt to build learning communities. Creating a social interaction environment can motivate students and help them self-monitor their learning. Most of the instructors used the discussion forum that was already provided by the platform. For instance, Joshua from the UK mentioned that,

We use a lot of resources that already exist. And then we use the MOOC discussion board as a place to where they, kind of, point out and say, "I've seen this. And this is useful. Well, I use this, and this is good well. I created this." 
Per the following quote, Henry from the UK used Padlet, a free collaboration tool, in his MOOCs, which might help student self-monitoring: "We have Padlet, which is a photo sharing platform, where people come up with their own photos and discuss them."

\section{Feedback Tools}

As mentioned above, feedback is critical for student SDL. MOOC instructors used formative and summative assessment technologies to help students' self-monitoring. Emily from the UK used progress bars in her MOOC to motivate students and help their self-monitoring. As she argued,

I think features like that and along with the weekly structure, that is the progress bar, taking off each item say, "I've completed it." They are all these little rewards as tiny as they are that helped to motivate you.

Andrew from the UK adopted learning analytics to monitor students' learning and revise his MOOC. In his interview, he stated, "We looked at the learner analytics and we decided to change the rhythm of the MOOC on the second run."

\section{Discussion and Limitations}

Several limitations of this study exist. First, participant information was collected from several key MOOC vendors' websites, including Coursera, FutureLearn, and edX, while those not in English, like XuetangX, were excluded. In addition, while acceptable for an opt-in survey (Cho \& LaRose, 1999), the survey completion rate was just $10 \%$, though it was markedly higher, at $18.2 \%$, when considering the number of email requests that were actually opened. Finally, this study only reported strategies MOOC instructors mentioned that they used to facilitate student self-monitoring; we could not verify whether the strategies that MOOC instructors reported were effective or not, nor could we confirm if they actually were utilized.

The first research question of this study focused on how instructors design and deliver MOOCs to facilitate students' self-monitoring skills for SDL. Even though many participants in this study had limited MOOC design and teaching experiences, they drew ideas from their previous traditional classroom teaching experience as well as any blended or online experience to facilitate student self-monitoring in MOOCs. Importantly, this study found that MOOC instructors reported that they facilitated students' self-monitoring by helping students with both internal feedback and external feedback. Students' internal feedback refers to their cognitive and metacognitive processing, which includes monitoring their learning strategies and an ability to think about their thinking (Garrison, 1997). Schraw, Crippen, and Hartley (2006) defined cognitive skills as having three components: (1) cognitive strategies, (2) problem-solving strategies, and (3) critical thinking skills. They stated that cognitive strategies refer to skills used to improve learning. In contrast, they noted that problem-solving strategies are more focused on solving complex and authentic problems. Third, Schraw and his colleagues argued that critical thinking refers to skills such as identifying and analyzing information critically.

To facilitate learners' cognitive learning processes, MOOC instructors reported that strategies such as quizzes for self-assessment, progress indicators, tutorials on technology use, learning tips, navigational aids for the course, instructional modeling, and various other resources and supports were used. MOOC instructors reported that self-assessment and progress indicators gave their participants a chance to review their work and monitor their learning process. Such 
results align with the findings of Kulkarni et al. (2013). Other scholars have claimed that selfassessment helps students reflect on their learning and achievement (Pintrich \& Zusho, 2002; Zimmerman \& Schunk, 2001) and offers students a learning opportunity that they could not obtain from external feedback (Dow et al., 2012).

In addition, instructional modeling was used in MOOCs to assist student cognitive processing reported by instructors in this study. Importantly, famed social learning psychologist Albert Bandura (1997) stated that modeling could possibly elevate one's level of self-efficacy. Modeling refers to students intentionally learning from others through observation (Schraw et al., 2006). Modeling has proven effective for decades (Bandura, 1997; Jonassen, 1999; Merrill \& Gilbert, 2008), as it demonstrates new strategies that are potentially within reach of a learner. According to Schunk and Zimmerman (1996), modeling can be especially helpful for one's selfefficacy, especially if the model is of a similar ability level, such as one's peer. Such an alignment further helps student cognitive processing of the task or situation.

In terms of facilitating metacognitive processing, in the present study, MOOC instructors encouraged students to reflect and think critically by providing reflection questions, opportunities to reflect, and assistance in building a learning community. This finding aligns with insights from Parker et al. (1995), who found that encouraging reflection can improve student SDL skills. Similarly, Schraw (1998) argued that reflection plays a vital role in building student metacognitive knowledge and self-monitoring skills; reflection can be particularly effective when constant opportunities are provided to students (Kuhn, Schauble, \& Garcia-Mila, 1992). Likewise, Boud, Keogh, and Walker (2013) also emphasized the importance of using reflection to transfer the learning experience to novel settings and situations.

External feedback can both motivate students and help with their self-monitoring. To foster students' self-monitoring via external feedback mechanisms, MOOC instructors, teaching assistants, and peers were involved in the learning process. The instructors we surveyed and interviewed revealed that MOOC instructor and TA feedback can help MOOC participants identify key places for learning improvement. In addition, research indicates that when peer-assessment mechanisms are adopted, they can be beneficial to both the learners who provide the feedback and the learners who receive it (Barak \& Rafaeli, 2004; Dochy et al., 1999).

The second research question addressed the use of technology to facilitate self-monitoring. As mentioned in the current study findings, MOOC instructors leveraged a variety of technologies to facilitate self-monitoring for SDL. Such technologies included: (1) synchronous communication technologies, (2) asynchronous communication technologies, and (3) feedback tools.

These three types of technologies served different purposes. First, the data indicated that these technologies support building a community of learners. MOOC instructors reported that the synchronous technologies, such as Google Hangouts and YouTube Live, as well as asynchronous communication technologies, such as discussion forums, blogs, Padlet, Slackbot, and various social media (e.g., Facebook), were functioning as communication technologies that could support students' interaction and communication. Such results align with the findings of Blaschke (2012) and Junco, Heiberger, and Loken (2010), who found that using social media can support student SDL. These results are also backed up by decades of research on social learning theory from Bandura (1977) and his colleagues (e.g., Schunk \& Zimmerman, 1996), which emphasizes that people learn from others through observation, imitation, and modeling. In addition, our findings support Candy's (1991) view that SDL is realized in collaboration and interaction; today, however, 
such collaborations and interactions are increasingly happening online.

Besides employing synchronous and asynchronous communications and conferencing technology to build a community of learners, commonly used feedback tools, such as progress bars and learning analytics, might help students with self-monitoring for SDL in MOOCs. In addition to using vendor-supported technology, many prior researchers have designed specific tools to support students SDL in MOOCs (e.g., Gutiérrez-Rojas, Alario-Hoyos, Pérez-Sanagustín, Leony, \& Delgado-Kloos, 2014). It is increasingly clear that technology, whether purchased from a vendor or designed by the instructor, can play an important role in student self-monitoring for SDL. Given that previous studies have indicated that technology can predict student SDL (Rashid \& Asghar, 2016) and engagement (Chen, Lambert, \& Guidry, 2010; Clements, 2015), including selfmonitoring, such a role is becoming vital to learner success in open and distance forms of learning today. Accordingly, MOOC instructors and instructional designers need to continue to explore and uncover ways to appropriately leverage technologies for self-monitoring for SDL.

\section{Conclusions and Future Directions}

This study offers insights into MOOC design and delivery to facilitate student selfmonitoring for SDL. In addition, various technology tools and systems employed to facilitate selfmonitoring were also revealed. The findings provide implications for instructors or instructional designers concerning the design of MOOCs for self-monitoring. Of course, the online surveys, interviews, and document reviews were just the first steps in the process. Thus, we are expanding the current research study with additional MOOC instructor participants to further inform the design of more effective and engaging MOOCs. We are also in the midst of a study of students' perceptions of effective self-monitoring strategies to verify the strategies emphatically emphasized and detailed as well as those more casually mentioned by the instructors.

Given the expansion of MOOCs and other forms of open education during the past decade to more than 100 million learners enrolling in over 11,000 MOOCs in 2018 alone (Shah, 2019), the time is ripe for investigating whether cognitive and metacognitive processes needed to succeed in MOOCs can be enhanced and whether such skill enhancements might transfer to other learningrelated settings and situations. In effect, a goal of MOOC researchers engaged in these types of studies - as well as for MOOC educators - is for SDL skills to not only percolate, evolve, and thrive in MOOCs, but to become so ingrained in one's learning habits that they become part of one's approach to each and every learning task. As such, additional studies should investigate different direct and indirect feedback mechanisms and strategies, forms and types of instructional scaffolds, interaction and engagement features, modeling behaviors, and other mechanisms that can help in the design of MOOCs that facilitate participant self-monitoring for SDL. 


\section{References}

Bandura, A. (1977). Social learning theory. Englewood Cliffs, NJ: Prentice Hall.

Barak, M., \& Rafaeli, S. (2004). On-line question-posing and peer-assessment as means for webbased knowledge sharing in learning. International Journal of Human-Computer Studies, 61(1), 84-103. https://doi.org/10.1016/j.ijhcs.2003.12.005

Beaven, T., Codreanu, T., \& Creuzé, A. (2014). Motivation in a language MOOC: Issues for course designers. Retrieved from https://www.degruyter.com/downloadpdf/books/9783110422504/9783110422504.4/9783 110422504.4.pdf

Blaschke, L. M. (2012). Heutagogy and lifelong learning: A review of heutagogical practice and self-determined learning. The International Review of Research in Open and Distributed Learning, 13(1), 56-71. doi:10.19173/irrodl.v13i1.1076

Bonk, C. J., Lee, M. M., Reeves, T. C., \& Reynolds, T. H. (Eds.). (2015). MOOCs and open education around the world. New York: Routledge.

Bonk, C. J., Zhu, M., Kim, M., Xu, S., Sabir, N., \& Sari, A. (2018). Pushing toward a more personalized MOOC: Exploring instructor selected activities, resources, and technologies for MOOC design and implementation. The International Review of Research on Open and Distributed Learning (IRRODL), 19(4), 92-115. Retrieved from http://www.irrodl.org/index.php/irrodl/article/view/3439/4765

Boud, D., Keogh, R., \& Walker, D. (2013). Reflection: Turning experience into learning. New York, NY: Routledge.

Brockett, R. G., \& Hiemstra, R. (1991). Self-direction in adult learning: Perspectives on theory, research, and practice (Vol. 20). London: Routledge.

Candy, P. C. (1991). Self-direction for lifelong learning. A comprehensive guide to theory and practice. San Francisco, CA: Jossey-Bass.

Chang, M. M. (2007). Enhancing web-based language learning through self-monitoring. Journal of Computer Assisted Learning, 23(3), 187-196. doi:10.1111/j.1365-2729.2006.00203.x

Chen, P. S. D., Lambert, A. D., \& Guidry, K. R. (2010). Engaging online learners: The impact of Web-based learning technology on college student engagement. Computers \& Education, 54(4), 1222-1232. https://doi.org/10.1016/j.compedu.2009.11.008

Cho, H., \& LaRose, R. (1999). Privacy issues in Internet surveys. Social Science Computer Review, 17(4), 421-434. https://doi.org/10.1177/089443939901700402

Clements, J. C. (2015). Using Facebook to enhance independent student engagement: A case study of first-year undergraduates. Higher Education Studies, 5(4), 131-146. http://dx.doi.org/10.5539/hes.v5n4p131

Coleman M. C., \& Webber J. (2002). Emotional and behavioral disorders. Boston, MA: Pearson Education Company.

Creswell, J. W., \& Plano-Clark, V. L. (2017). Designing and conducting mixed methods research (3rd ed.). Thousand Oaks, CA: Sage. 
Delclos, V. R., \& Harrington, C. (1991). Effects of strategy monitoring and proactive instruction on children's problem-solving performance. Journal of Educational Psychology, 83(1), 35. Retrieved from https://psycnet.apa.org/buy/1991-19728-001

Dochy, F. J. R. C., Segers, M., \& Sluijsmans, D. (1999). The use of self-, peer and co-assessment in higher education: A review. Studies in Higher Education, 24(3), 331-350. https://doi.org/10.1080/03075079912331379935

Dow, S., Kulkarni, A., Klemmer, S., \& Hartmann, B. (2012, February). Shepherding the crowd yields better work. In Proceedings of the ACM 2012 conference on computer supported cooperative work (pp. 1013-1022). ACM. Retrieved from https://dl.acm.org/citation.cfm?id=2145355

Fischer, G. (2005). From reflective practitioners to reflective communities. In Proceedings of the HCI international conference (HCII), Las Vegas. Retrieved from http://13d.cs.colorado.edu/ gerhard/papers/reflective-communities-hcii-2005.pdf

Fischer, G., \& Sugimoto, M. (2006). Supporting self-directed learners and learning communities with sociotechnical environments. Research and Practice in Technology Enhanced Learning, 1(1), 31-64. Retrieved from https://pdfs.semanticscholar.org/0ed6/e061fc277045f4cc5e711bc7f539c60ec4a5.pdf

Fisher, M. J., \& King, J. (2010). The self-directed learning readiness scale for nursing education revisited: A confirmatory factor analysis. Nurse Education Today, 30(1), 44-48. doi:10.1016/j.nedt.2009.05.020

Fraenkel, J. R., \& Wallen, N. E. (2009). The nature of qualitative research. How to design and evaluate research in education (7th ed., p. 420). Boston: McGraw-Hill.

Garrison, D. R. (1997). Self-directed learning: Toward a comprehensive model. Adult Education Quarterly, 48(1), 18-33. Retrieved from http://journals.sagepub.com/doi/pdf/10.1177/074171369704800103

Guest, G., Bunce, A., \& Johnson, L. (2006). How many interviews are enough? An experiment with data saturation and variability. Field Methods, 18(1), 59-82. doi: $10.1177 / 1525822 \times 05279903$

Gutiérrez-Rojas, I., Alario-Hoyos, C., Pérez-Sanagustín, M., Leony, D., \& Delgado-Kloos, C. (2014). Scaffolding self-learning in MOOCs. Proceedings of the European MOOC Stakeholder Summit, 2014, 43-49. Retrieved from http://educate.gast.it.uc3m.es/wpcontent/uploads/2014/02/Scaffolding_self-learning_in_MOOCs.pdf

Haney, W., Russell, M., Gulek, C., \& Fierros, E. (1998). Drawing on education: Using student drawings to promote middle school improvement. Schools in the Middle, 7(3), 38-43. Retrieved from https://eric.ed.gov/?id=EJ561666

Hewitt-Taylor, J. (2001). Self-directed learning: Views of teachers and students. Journal of Advanced Nursing, 36(4), 496-504. https://doi.org/10.1046/j.1365-2648.2001.02001.x

Jonassen, D. (1999). Designing constructivist learning environments. In C. M. Reigeluth (Ed.), Instructional-design theories and models (Vol. II, pp. 215-239). Mahwah, NJ: Lawrence Erlbaum. 
Junco, R., Heiberger, G., \& Loken, E. (2011). The effect of Twitter on college student engagement and grades. Journal of Computer Assisted Learning, 27(2), 119-132. doi:10.1111/j.13652729.2010.00387.x

Kell, C., \& Deursen, R. V. (2002). Student learning preferences reflect curricular change. Medical Teacher, 24(1), 32-40. doi:10.1080/00034980120103450

Kop, R., \& Fournier, H. (2011). New dimensions to self-directed learning in an open networked learning environment. International Journal for Self-Directed Learning, 7(2), 1-19. Retrieved from https://docs.wixstatic.com/ugd/dfdeaf_b1740fab6ad144a980da1703639aeeb4.pdf

Kuhn, D., Schauble, L., \& Garcia-Mila, M. (1992). Cross-domain development of scientific reasoning. Cognition and Instruction, 9(4), 285-327. https://doi.org/10.1207/s1532690xci0904_1

Kulkarni, C., Wei, K. P., Le, H., Chia, D., Papadopoulos, K., Cheng, J., ... Klemmer, S. R. (2013). Peer and self-assessment in massive online classes. ACM Transactions on Computer-Human Interaction (TOCHI), 20(6), 33. http://dx.doi.org/10.1145/2505057

Leech, N. L., \& Onwuegbuzie, A. J. (2007). An array of qualitative data analysis tools: A call for data analysis triangulation. School Psychology Quarterly, 22(4), 557. doi:10.1037/10453830.22.4.557

Loizzo, J., Ertmer, P. A., Watson, W. R., \& Watson, S. L. (2017). Adult MOOC learners as selfdirected: Perceptions of motivation, success, and completion. Online Learning, 21(2). doi:10.24059/olj.v21i2.889

Lunyk-Child, O. I., Crooks, D., Ellis, P. J., Ofosu, C., \& Rideout, E. (2001). Self-directed learning: Faculty and student perceptions. Journal of Nursing Education, 40(3), 116-123. doi:10.3928/0148-4834-20010301-06

Maag, J. W., Rutherford, R. B., Jr., \& Digangi, S. A. (1992). Effects of self-monitoring and contingent reinforcement on on-task behavior and academic productivity of learning disabled students: A social validation study. Psychology in the Schools, 29(2), 157-172. https://doi.org/10.1002/1520-6807(199204)29:2<157::AID-PITS2310290211>3.0.CO;2$\underline{\mathrm{F}}$

Malone, L. D., \& Mastropieri, M. A. (1991). Reading comprehension instruction: Summarization and self-monitoring training for students with learning disabilities. Exceptional Children, 58(3), 270-279. https://doi.org/10.1177/001440299105800309

Margaryan, A., Bianco, M., \& Littlejohn, A. (2015). Instructional quality of massive open online courses (MOOCs). Computers \& Education, 80, 77-83. doi:10.1016/j.compedu.2014.08.005

Merriam, S. B. (1988). Case study research in education: A qualitative approach. San Francisco, CA: Jossey-Bass.

Merriam, S. B. (2001). Andragogy and self-directed learning: Pillars of adult learning theory. New Directions for Adult and Continuing Education, 2001(89), 3-14. doi:10.1002/ace.3

Merriam, S. B. (2009). Qualitative research: A guide to design and implementation. San Francisco, CA: Jossey-Bass. 
Merrill, M. D., \& Gilbert, C. (2008). Effective peer interaction in a problem-centered instructional strategy. Distance Education, 29(2), 199-207.

doi:10.1080/01587910802154996

Parker, D. L., Webb, J., \& D’Souza, B. (1995). The value of critical incident analysis as an educational tool and its relationship to experiential learning. Nurse Education Today, 15(2), 111-116. doi: 10.1016/S0260-6917(95)80029-8

Patton, M. Q. (2002). Two decades of developments in qualitative inquiry: A personal, experiential perspective. Qualitative Social Work, 1(3), 261-283. https://doi.org/10.1177/1473325002001003636

Pintrich, P. R., \& Zusho, A. (2002). Student motivation and self-regulated learning in the college classroom. In J. C. Smart (Ed.), Higher education: Handbook of theory and research (pp. 55-128). Springer, Dordrecht.

Prociuk, J. L. (1990). Self-directed learning and nursing orientation programs: Are they compatible? The Journal of Continuing Education in Nursing, 21(6), 252-256. doi:10.3928/0022-0124-19901101-07

Puzziferro, M. (2008). Online technologies self-efficacy and self-regulated learning as predictors of final grade and satisfaction in college-level online courses. The American Journal of Distance Education, 22(2), 72-89. doi:10.1080/089236408020390

Rashid, T., \& Asghar, H. M. (2016). Technology use, self-directed learning, student engagement and academic performance: Examining the interrelations. Computers in Human Behavior, 63, 604-612. https://doi.org/10.1016/j.chb.2016.05.084

Rohs, M., \& Ganz, M. (2015). MOOCs and the claim of education for all: A disillusion by empirical data. The International Review of Research in Open and Distributed Learning, 16(6). doi:10.19173/irrodl.v16i6.2033

Ross, J., Sinclair, C., Knox, J., \& Macleod, H. (2014). Teacher experiences and academic identity: The missing components of MOOC pedagogy. MERLOT Journal of Online Learning and Teaching, 10(1), 57. Retrieved from http://jolt.merlot.org/vol10no1/ross_0314.pdf

Schon, D. A. (1983). The reflective practitioner: How professionals think in action. New York: Basic Books.

Schraw, G. (1998). Promoting general metacognitive awareness. Instructional Science, 26(1-2), 113-125. Retrieved from https://link.springer.com/article/10.1023/A:1003044231033

Schraw, G., Crippen, K. J., \& Hartley, K. (2006). Promoting self-regulation in science education: Metacognition as part of a broader perspective on learning. Research in Science Education, 36(1-2), 111-139. doi:10.1007/s11165-005-3917-8

Schunk, D. H. (1982). Progress self-monitoring: Effects on children's self-efficacy and achievement. The Journal of Experimental Education, 51(2), 89-93. https://doi.org/10.1080/00220973.1982.11011845 
Schunk, D. H., \& Zimmerman, B. J. (1996). Modeling and self-efficacy influences on children's development and self-regulation. In J. Juvonen \& K. Wentzel (Eds.), Social motivation: Understanding children's school adjustment (pp. 154-180). Cambridge, England: Cambridge University Press.

Shah, D. (2017). MOOCs find their audience: Professional learners and universities. Class Central. Retrieved from https://www.classcentral.com/report/moocs-find-audienceprofessional-learners-universities/

Shah, D. (2019). Year of MOOC-based degrees: A review of MOOC stats and trends in 2018. Class Central. Retrieved from https://www.class-central.com/report/moocs-stats-andtrends-2018/

Sze-Yeng, F., \& Hussain, R. M. R. (2010). Self-directed learning in a socioconstructivist learning environment. Procedia-Social and Behavioral Sciences, 9, 1913-1917. doi:10.1016/j.sbspro.2010.12.423

Terras, M. M., \& Ramsay, J. (2015). Massive open online courses (MOOCs): Insights and challenges from a psychological perspective. British Journal of Educational Technology, 46(3), 472-487. doi: 10.1111/bjet.12274

Watson, S. L., Loizzo, J., Watson, W. R., Mueller, C., Lim, J., \& Ertmer, P. A. (2016). Instructional design, facilitation, and perceived learning outcomes: An exploratory case study of a human trafficking MOOC for attitudinal change. Educational Technology Research and Development, 64(6), 1273-1300. doi:10.1007/s11423-016-9457-2

Williamson, S. N. (2007). Development of a self-rating scale of self-directed learning. Nurse Researcher, 14(2), 66-83. Retrieved from https://search.proquest.com/openview/c7980aea8ee20b570c57e9102cf5b9ea/1?pqorigsite $=$ gscholar\&cbl $=33100$

Zimmerman, B. J. (1999) Commentary: Toward a cyclically interactive view of self-regulated learning. International Journal of Educational Research 31, 545-551.

Zimmerman, B. J., \& Paulsen, A. S. (1995). Self-monitoring during collegiate studying: An invaluable tool for academic self-regulation. New Directions for Teaching and Learning, 1995(63), 13-27. https://doi.org/10.1002/t1.37219956305

Zimmerman, B. J., \& Schunk, D. H. (Eds.). (2001). Self-regulated learning and academic achievement: Theoretical perspectives. New York, NY: Routledge.

Zhu, M., Bonk, C. J., \& Sari, A. R. (2018). Instructor experiences designing MOOCs in higher education: Pedagogical, resource, and logistical considerations and challenges. Online Learning, 22(4), 203-241. doi:10.24059/olj.v22i4.1495

Zhu, M., \& Bonk, C. J. (2019). Designing MOOCs to facilitate participant self-directed learning: An analysis of instructor perspectives and practices. International Journal of SelfDirected Learning, 16(2), 39-60. Retrieved from http://publicationshare.com/pdfs/Designing-MOOCs-for-SDL.pdf 


\section{Appendix \\ Interview Protocol}

\section{Instructor Background}

1. Could you please briefly introduce yourself?

2. What is your experience with designing MOOCs?

\section{Design and SDL}

3. What kinds of students do you think have taken/are taking/will be taking the MOOC?

4. What's your understanding about self-directed learning (SDL)?

\section{Provide definition:}

Based on Garrison's (1997) self-directed learning model, SDL has three overlapping aspects: (1) self-management (task control); (2) self-monitoring (cognitive responsibility); and (3) motivating (both entering motivation and task motivation).

Self-management is related to task control, such as the management of learning time, resources, and support.

Self-monitoring involves cognitive and metacognitive processes which includes monitoring the learning strategies and the ability to think about thinking. For example, learners know how to set up their learning goals and evaluate their learning.

Motivation can initiate and maintain the effort toward learning and realizing cognitive goals, such as learners' motivation of taking MOOCs, engagement in the course tasks.

5. What types of self-directed learning skills might prove beneficial when taking a MOOC?

6. What do you think of the responsibility of instructors to facilitate students' SDL skills in MOOCs?

7. How do you think the design and delivery of your MOOC can help develop students' self-management skills such as time, resources, and support? Could you please give me a specific example in designing or developing your MOOC that might have had a direct or indirect impact on these skills?

8. In the previous survey, you mentioned the design and delivery of your MOOC can help students to set their own learning goals. Could you please give me a specific example in designing or developing your MOOC that might have had a direct or indirect impact on these skills?

9. How do you think the design and delivery of your MOOC can help develop students' self-control skills, such as monitoring learning strategies and learning paces? Could you please give me a specific example in designing or developing your MOOC that might have had a direct or indirect impact on these skills?

10. In the previous survey, you mentioned the design and delivery of your MOOC can help students to evaluate their own learning and performance. Could you please give me a 
specific example in designing or developing your MOOC that might have had a direct or indirect impact on these skills?

11. How do you think the design and delivery of your MOOC can motivate students? Could you please give me a specific example in designing or developing your MOOC that might have had a direct or indirect impact on these skills?

12. How is technology being used to help students' SDL skills?

13. What technology features or functions do you want to have to help students' SDL skills?

14. If a new MOOC instructor is going to design and teach a new MOOC, what suggestions do you have to help them to design and teach a MOOC that facilitate students' SDL skills? 